\title{
APRENDENDO COM A EXPERIÊNCIA? A ATUAÇÃO DA SANDF NA MONUSCO E SEU IMPACTO NAS RELAÇÕES CIVIS-MILITARES DA ÁFRICA DO SUL'
}

\author{
LEARNING FROM EXPERIENCE? THE AGENCY OF SANDF IN MONUSCO \\ AND ITS IMPACT ON CIVIL-MILITARY RELATIONS OF SOUTH AFRICA
}

DOI: $10.5380 / c g . v 10 i 1.76341$

\author{
Julio Cesar Ribeiro Mota Filho²
}

\begin{abstract}
Resumo
Esta pesquisa propõe-se a verificar em quais aspectos a experiência da Força Nacional de Defesa da África do Sul (SANDF) na Missão das Nações Unidas na República Democrática do Congo (MONUSCO) contribui para a concretização dos anseios civis sobre os militares na África do Sul pós-apartheid. Para este empreendimento, o estudo de caso apoia-se sobre os pressupostos teóricos de Bruneau e Matei (2008) e guia-se por meio de metodologia qualitativa pautada em análise documental reunida em procedimento de revisão narrativa. $\mathrm{O}$ artigo está dividido em duas partes principais, além de introdução e conclusão. Na introdução, contextualizamse as inflexões políticas que ocorreram na África do Sul pós-apartheid e questões metodológicas que guiarão este trabalho. Após realizada essa etapa, aspectos teóricos das relações civis-militares são apresentados na primeira parte. Na segunda parte, os impactos da missão da SANDF na MONUSCO para efetividade militar, eficiência, mecanismos de monitoramento e controle civil na África do Sul são analisados. Por último, as considerações finais desta pesquisa são realizadas, as quais estabelecem que, apesar de ter parcialmente contribuído para a consolidação dos anseios civis em relação à efetividade e ao controle dos militares por meio dos mecanismos formais de monitoramento, a experiência da SANDF na MONUSCO tem gerado impacto negativo para a ratificação da eficiência, a qual tem, consequentemente, atenuado os ganhos advindos dos esforços formais de supervisão de Pretória sobre o controle dos militares na África do Sul pós-apartheid, colocando o Estado em uma situação de dubiedade em relação ao adequado controle civil e à harmonia das relações civis-militares.
\end{abstract}

Palavras-Chave: Relações civis-militares; SANDF; MONUSCO.

\begin{abstract}
This research proposes to verify which aspects of the South African National Defense Force (SANDF) experience in United Nations Organization Stabilization Mission in the DR CONGO (MONUSCO) has contributed to the civil wishes achievement upon the militaries in post-apartheid South Africa. For this purpose, this case study leans on Bruneau and Matei (2008) theoretical assumptions and guides itself through a qualitative methodology based on documental analysis reunited by a narrative review procedure. This article is divided into two major parts, besides the introduction and final remarks. In the introduction, one contextualizes the political inflections that occurred in post-apartheid South Africa and the methodological matters that guide this work. Henceforth, theoretical aspects of civil-military relations are presented in the first part. In the second part, one evaluates the impacts of SANDF in MONUSCO for military effectiveness,
\end{abstract}

\footnotetext{
${ }^{1}$ Artigo originado de uma pesquisa parcialmente financiada com recursos da Coordenação de Aperfeiçoamento de Pessoal de Nível Superior (CAPES). Este artigo está licenciado sob a Licença Creative Commons Attribution (CC BY 4.0), sendo permitido o compartilhamento com reconhecimento da autoria e publicação inicial nesta revista.

${ }^{2}$ Mestrando em Relações Internacionais pela Universidade Federal de Santa Catarina (UFSC) e bacharel em Relações Internacionais pela mesma instituição. E-mail: juliocesarmfilho@outlook.com. ORCID: https://orcid.org/0000-0003-3216-407X.
} 
efficiency, surveillance mechanisms, and civil control in South Africa. Lastly, final remarks of this research are made, which states that although it has partially contributed to civil wishes concerning effectiveness and control over the military through formal surveillance mechanisms, the experience of SANDF in MONUSCO has produced negative impact for the ratification of efficiency, which has, consequently, dampen the gains stemmed from Pretoria's formal supervision efforts over the militaries in post-apartheid South Africa, placing the State in a dubious situation about an adequate civil control and harmonious civil-military relations.

Keywords: Civil-military relations; SANDF; MONUSCO.

\section{INTRODUÇÃO}

O fim do regime racista na África do Sul trouxe notáveis inflexões políticas para Pretória e para a região da África Austral como um todo. As políticas do apartheid, pressionadas pela estagnação econômica doméstica, boicotes da comunidade internacional e confronto de movimentos negro, sindical e estudantil, tiveram seu fim anunciado quando De Klerk retirou o Congresso Nacional Africano (CNA) da ilegalidade e libertou Nelson Mandela em fevereiro de 1990 (CALLINICOS, 1994).

Apesar de terem sido marcados por incidentes violentos e travas nas negociações para a transição política, os anos que se seguiram desembocaram, em maio de 1994, na inauguração de um regime político baseado na vontade da maioria e na eliminação dos últimos vestígios formais de dominação colonial na África do Sul (CALLINICOS, 1994). Sob a presidência de Nelson Mandela, a nova Pretória encarregou-se de promover mudanças nas instituições sul-africanas, inclusive nas Forças Armadas, as quais eram fator de instabilidade regional e atendiam aos anseios da minoria branca africâner representada pelo Partido Nacional nos tempos do apartheid.

Como destaca Otávio (2017), o CNA foi o responsável por substituir a Força de Defesa da África do Sul (SADF) pela Força Nacional de Defesa da África do Sul (SANDF). Tal transformação possuiu duas características:

\footnotetext{
a primeira diz respeito à mudança de paradigma acerca do conceito de segurança, [...] a SANDF espelha um novo processo de inserção sul-africana no continente, no qual Pretória encontra-se voltado ao desejo de desenvolver um importante papel no combate às mazelas da África [...], bem como à manutenção da paz no continente. [...] Um segundo ponto a ser destacado nesta transformação diz respeito à inclusão nos quadros militares de ex-combatentes do regime do apartheid [...] (OTAVIO, 2017, p. 300).
}

Nesse sentido, o processo de remodelamento militar, iniciado em 1994, foi realizado por meio da união de sete Forças Armadas, as quais eram divididas em dois grandes grupos: os defensores do apartheid - SADF e as Forças das Homelands (Transkei, Venda, Bophuthatswana e Ciskei) e os opositores de tal regime - APLA (Exército de Libertação Popular Azaniano) e MK (Lança da Nação) (MASHIKE, 2007). Essa fusão, ou assimilação à SADF, como destaca Mashike (2007), foi acompanhada de um processo de encolhimento do número de efetivos, por meio da não renovação 
de contratos de soldados dos grupos armados, além de forte reestruturação do ethos militar. A SADF, branca e guiada pelos imperativos de profissionalismo e eficiência no combate, deveria, a partir daquele momento, representar a multiculturalidade da África do Sul e guiar-se pelo respeito aos direitos humanos e pela subordinação inequívoca à sociedade civil e ao regime democrático (FRANKEL, 2000).

Refletindo os princípios de transformação dos serviços públicos Batho Pele ${ }^{3}$, esses novos anseios da classe política para as Forças Armadas concretizaram-se nas reformas do setor de segurança do país em 1998, 2012 e 2015, chamadas de defence review. Sob a égide desses documentos, as operações de paz foram tratadas como importante instrumento para operacionalização dos novos objetivos da SANDF4 ${ }^{4}$ Nesse sentido, a SANDF tem atuado em diversas operações de paz na era pós-apartheid. Esse tipo de atuação das tropas sul-africanas vem ocorrendo no âmbito da Comunidade de Desenvolvimento para a África Austral (SADC), União Africana (UA) e Organização das Nações Unidas (ONU), como, por exemplo, no Lesotho (Operação Boleas), Burundi (AMIB) e na República Democrática do Congo (MONUC/MONUSCO) respectivamente.

Como mostra Heinecken (2020), as experiências no terreno das Forças Armadas são um importante fator no modelamento da organização militar de um Estado. Nesse sentido, com participação sul-africana tanto em sua origem quanto em sua reformulação (2010) ${ }^{5}$, a Missão das Nações Unidas na República Democrática do Congo (MONUSCO) é importante ferramenta para avaliar em que medida a atuação da SANDF contribuiu para cimentação dos anseios civis quanto ao papel dos militares após as reformas do setor de segurança da África do Sul.

O objetivo deste trabalho é analisar, por meio dos pressupostos teóricos de Bruneau e Matei (2008), o impacto da atuação dos soldados de Pretória nessa missão de paz para a consolidação da efetividade, eficiência e controle das relações civis-militares após a transformação da SADF em SANDF. Para este estudo de caso, os elementos empíricos são extraídos de pesquisa documental e marginalmente - de pesquisa bibliográfica sobre o tema. Enquanto esta compreende um tratamento

\footnotetext{
3 O princípio Batho Pele (People First) compreende um conjunto de normas que buscou transformar o serviço público, inclusive o das Forças Armadas, na África do Sul após o fim do apartheid, guiando-se por meio da transparência, informação, reparação, padronização e cortesia. (TSHABALALA, 2004).

4 O defence review de 1998 dispõe que uma das tarefas da SANDF é "promover segurança internacional por meio da participação em operações de paz e cooperação militar em apoio à política externa (ÁFRICA DO SUL, 1998, Cap. III - 5.4, tradução nossa) No original: "to promote international security through participation in peace operations and military co-operation in support of foreign policy”. A edição de 2015 coloca ainda mais em evidência tal função das Forças Armadas, as quais serviriam aos propósitos de construir uma Agenda Africana. A partir de então, as Operações de Paz seriam um dos objetivos centrais de Pretória em matéria de segurança. Nessa questão, o documento dispõe que "a Defesa buscará reconstrução e criará condições propícias à paz a longo prazo e construção de segurança em apoio dos objetivos de [missões] de manutenção da paz" (ÂFRICA DO SUL, 2015, cap. VI-p.8, tradução nossa). No original: "Defence will pursue reconstruction and create conditions conducive to long-term peace and security building in support of peace keeping objectives".

5 Em 2010, a MONUSCO sucedeu à MONUC por meio da Resolução No 1925 do Conselho de Segurança da ONU (ONU, 2020).
} 
analítico de primeira mão de fontes originárias dispersas e diversificadas, aquela resume-se em conteúdo sobre determinado assunto produzido por acadêmicos, como artigos e livros (GIL, 2008).

Em relação à análise documental, Gil (2008) destaca que esta possui vantagens pelo baixo custo de realização e possibilidade de tratamento de um tema quando o contato com os sujeitos da pesquisa é dificultoso. A escolha dos documentos pautou-se pela revisão narrativa, a qual permite que o autor trate de maneira crítica os materiais sem necessidade de uma busca sistematizada e exaurível das fontes disponíveis (UNESP, 2015). Nesse sentido, foram escolhidas fontes oficiais dos poderes Executivo e Legislativo da África do Sul disponibilizadas ao público por meio da internet, bem como de veículos de imprensa (DefenceWeb e IOL) que trataram do objeto de estudo deste trabalho. Em relação ao recorte temporal, optou-se por analisar informações da década de 2010, uma vez que é nesse período em que a MONUSCO passou a existir, sucedendo a extinta MONUC em maio de 2010. Cabe ressaltar que tais fontes, apesar de não esgotarem as informações disponíveis sobre o tema e de possuírem certo grau de subjetividade como qualquer tipo de produção, são geralmente aceitas como recursos legítimos em uma pesquisa documental.

Com essa estratégia de pesquisa, será demonstrado ao longo do trabalho que é possível afirmar a existência de evidências de que, apesar de ter parcialmente contribuído para a consolidação dos anseios civis em relação à efetividade e ao controle dos militares por meio dos mecanismos formais de monitoramento, a experiência da SANDF na MONUSCO tem gerado impacto negativo para a ratificação da eficiência, a qual tem, consequentemente, atenuado os ganhos advindos dos esforços formais de supervisão de Pretória sobre o controle dos militares na África do Sul pósapartheid, colocando o Estado em uma situação de dubiedade em relação ao adequado controle civil e à harmonia das relações civis-militares.

\section{ASPECTOS TEÓRICOS DAS RELAÇÕES CIVIS-MILITARES}

Antes de a relação do objeto de pesquisa com a teoria utilizada neste trabalho ser abordada, convém relembrar alguns pensamentos fundadores das relações civis-militares. Nesse sentido, a obra de Huntington (2000) ganha destaque.

Publicado pela primeira vez em 1957, "The Soldier and the State” é um apelo à sofisticação da profissionalização dos militares nos EUA, os quais, segundo o autor, estavam sofrendo desprestígio e abalamento moral por conta das tentativas de incorporação de aspectos políticos na carreira dos oficiais no pós-Segunda Guerra Mundial. Sob um contexto de Guerra Fria, Huntington (2000) advoga pela necessidade de inflexão conservadora no círculo das Forças Armadas para a garantia do controle e da profissionalização dos militares, pois, para o autor, o antimilitarismo da época colocava a segurança dos EUA sob risco. A solução para tal problema seria suplantar as ideologias liberais por um novo conservadorismo, que se traduziria em cautela, sanidade e realismo 
na carreira militar; representando uma volta aos anos anteriores à Segunda Guerra Mundial (HUNTINGTON, 2000).

Segundo o autor, os oficiais possuem um aspecto profissional distinto das demais profissões civis, pois lidam diretamente com a administração do uso da força do Estado. Dessa forma, para restaurar a integridade militar e garantir a segurança do Estado, a vedação dos oficiais aos assuntos civis torna-se fundamental. Nas palavras do acadêmico, "[...] uma corporação de oficiais [...] faltando prestígio, mas sensível aos apelos da popularidade colocaria em risco a segurança do Estado” (HUNTINGTON, 2000, p. 11, tradução nossa) ${ }^{6}$.

Ao contrário da posição absolutista de Huntington, Janowitz aborda o controle das relações civis-militares pragmaticamente. Sua obra clássica, "The Professional Soldier", sinaliza para a progressiva e inevitável civilinização da carreira militar nos Estados Unidos, causada pelos novos valores da sociedade, avanço da tecnologia, popularização do recrutamento e pelas novas maneiras de se fazer a guerra (TRAVIS, 2018). É que para Janowitz (2017), os conflitos que envolvem as Forças Armadas dos EUA no pós-Segunda Guerra Mundial deixaram de demandar o cerimonialismo, rigidez e tradicionalismo da carreira militar. Na esteira desse raciocínio, o autor trabalha o conceito de operações constabulares, nas quais há o emprego das Forças Armadas em ações de caráter policial, distanciando-se dos modelos de combate tradicional da primeira metade do século XX (JANOWITZ, 2017).

Segundo o autor, a restauração do prestígio e profissionalização da carreira militar há de levar em conta essa nova realidade. Nesse sentido, Janowitz (2017) argumenta que há plena compatibilidade entre as ações constabulares e os objetivos democráticos e de controle político sobre os militares. Além disso, para que o estreitamento de laços entres os militares e a sociedade civil dos EUA seja possível, é necessário que ambos compartilhem os mesmos valores (YOUNG, 1960).

Neste trabalho, acredita-se que as ideias de Janowitz (2017) melhor representam a realidade da organização militar no mundo contemporâneo do que o argumento asséptico da separação civilmilitar de Huntington (2000). No entanto, apesar dos acadêmicos acima serem considerados clássicos na literatura sobre o tema, seus pressupostos teóricos devem ser expandidos para a incorporação de novos elementos de análise que vão além do controle.

O controle é, de fato, um elemento fundamental nas relações civis-militares em democracias. No entanto, como alegam Bruneau e Matei (2008, p. 909, tradução nossa), é necessário dar atenção ao que forças de segurança fazem e a que custo, ou seja, sua efetividade e eficiência e implicações de seus papéis e missões para a democracia7.

\footnotetext{
${ }^{6}$ No original: "[...] a political office corps [..] lacking prestige but sensitive to the appeals of popularity would endanger the security of State".

7 No original: "to what security forces do, and at what cost, that is, their effectiveness and efficiency, and the implications of their roles and missions for democracy".
} 
Portanto, é importante analisar conjuntamente os elementos de controle, efetividade e eficiência ${ }^{8}$ para identificar se as ações militares na MONUSCO estão ratificando os anseios dos líderes políticos civis na África do Sul pós-apartheid.

Na concepção desses autores, controle significa a supremacia civil sobre os mecanismos institucionais de controle, supervisão, e normas profissionais. (BRUNEAU; MATEI, 2008). Cabe ressaltar que, segundo Bland (2001), tais mecanismos não são suficientes por si só, uma vez que o controle civil depende de uma interconexão entre esses instrumentos formais (hardware) e aspectos ideacionais a nível individual (software), tanto do corpo político, quanto do corpo militar. Isto é: de nada adianta vários aparatos institucionais para garantir a supremacia civil sobre os militares se os valores e a cultura da sociedade são incompatíveis com tais prescrições formais. Portanto, é pertinente unir os argumentos de Bland (2001) aos de Bruneau e Matei (2008) para uma observação mais ampla do elemento controle nas relações civis-militares.

Quanto ao termo efetividade, Bruneau e Matei (2008, p. 917, tradução nossa) afirmam ser um elemento de difícil mensuração, mas pode ser compreendido como uma avaliação se a organização militar possui a capacidade de cumprir as funções demandadas pelos líderes civis, inclusive, de "preparar-se e executar operações de apoio à paz"9. O último termo, eficiência, mede quão bem o objetivo de uma missão foi realizado e debruça-se sobre a quantidade de recursos dispendidos nas operações militares. Para haver eficiência é necessário, segundo Bruneau e Matei (2008, p. 920, tradução nossa), que as instituições do governo "lidem com a alocação e supervisão desses recursos"10. Ademais, Matei (2012) afirma que a eficiência ocorre quando os militares conseguem alcançar os objetivos a um custo mínimo.

Neste artigo, amplia-se o escopo desta definição ao interpretar que a eficiência é um elemento que vai além da avaliação dos custos econômicos diretos. Fatores como disciplina e profissionalização também impactam a avaliação de quão bem uma missão foi cumprida pelos militares, além de influenciarem, ainda que indiretamente, na utilização de recursos em uma operação.

Quanto a esse conceito, cabe fazer algumas observações. Entende-se que não é possível haver eficiência sem efetividade, pois sua existência pressupõe o cumprimento das funções demandadas pelos líderes civis. Nesse sentido, pode-se argumentar que nem todas operações com efetividade são eficientes, mas todas operações eficientes possuem efetividade.

Nas próximas seções, os conceitos de controle, efetividade e eficiência serão usados como ferramentas de análise sobre a atuação da SANDF na MONUSCO. No entanto, como evidenciam Bruneau e Croissant (2019), os critérios utilizados para avaliação dos três elementos citados acima ainda não estão pacificados na literatura.

\footnotetext{
8 No artigo de Bruneau e Matei (2008), os termos controle, efetividade e eficiência são originalmente nomeados como control, effectiveness and efficiency.

9 No original: "prepare for and execute peace support operations".

${ }^{10}$ No original: "deal with the allocation and oversight of these resources".
} 
Desse modo, é pertinente afirmar que não é propósito deste artigo esgotar as possibilidades de análise quanto ao controle, efetividade e eficiência das Forças Armadas da África do Sul. Tomouse a liberdade de trabalhar apenas determinadas características de cada aspecto das relações civismilitares delineados majoritariamente por Bruneau e Matei (2008), as quais serão detalhadas nas páginas seguintes.

\section{MONUSCO E O IMPACTO SOBRE A EFETIVIDADE, EFICIÊNCIA E CONTROLE DOS MILITARES}

\subsection{PONDERAÇÕES SOBRE EFETIVIDADE E EFICIÊNCIA}

Primeiramente, no intuito de avaliar a efetividade, é necessário verificar se as Forças Armadas de um Estado estão preparadas e cumprirão os papéis designados pela classe política, inclusive, "os de executar operações de apoio e manutenção da paz e estabilidade, e intervenções humanitárias" (BRUNEAU; CROISSANT, 2019, p. 5, tradução nossa) ${ }^{11}$. Dessa forma, cabe investigar se a atuação da SANDF na MONUSCO atendeu aos objetivos delineados por Pretória para comensurar se os soldados sul-africanos foram efetivos em sua missão.

Como consta no Relatório Anual de Defesa, a atuação da SANDF na RDC encaixa-se nas estratégias de médio prazo em matéria de segurança da África do Sul, a qual espera que a missão contribua "para uma África melhor e mais segura em um mundo melhor" (DEPARTAMENTO DE DEFESA, 2019, p. 38, tradução nossa) ${ }^{1213}$ Mais especificamente, a Operação Mistral busca construir a paz em um dos principais palcos de guerra da África, protegendo civis e desmantelando grupos rebeldes (M23, ADF, FRPI, LRA e FDLR) por meio da MONUSCO, em específico, na Brigada de Intervenção. Quanto aos resultados obtidos, o discurso oficial da África do Sul sustenta que a atuação dos militares tem sido efetiva na missão. Em coletiva para a imprensa, a ministra Nqakula (2014) afirmou que a SANDF teve um papel central na derrota do M23 na RDC. Corroborando com essa visão, o sargento Tlhaole sustenta que (2019, p. 9, tradução nossa), “depois da operação, o grupo M23 pôs um fim a sua rebelião de 20 meses, dizendo que iria desarmar-se e buscar diálogos para a paz"14.

\footnotetext{
${ }^{11}$ No original: to execute [...] peacekeeping and stability and support operations, and humanitarian interventions".

12 No original: "to a better and safer Africa in a better World".

${ }_{13}$ Respectivamente: Movimento 23 de Março; Forças Democráticas Aliadas; Força de Resistência Patriótica de Ituri, Insurgência em Uganda e Forças Democráticas pela Libertação de Ruanda.

14 "after the operation, the M23 group called an end to its 20-month rebellion, saying it would disarm and pursue peace talks".
} 
No entanto, há fortes controvérsias sobre a efetividade das operações da SANDF. Segundo Tull (2017), a derrota definitiva do M23 não aconteceu. Na verdade, o que houve foi a diminuição de suas atividades, não como consequência das operações contra o grupo, mas sim por conta das pressões diplomáticas sobre Ruanda, seu principal apoiador. O Consultor Político Sênior da ONU para a MONUSCO, Adam Day, vai ao encontro do argumento de Tull ao sustentar que a retirada do financiamento de Ruanda foi fator-chave na desarticulação do M23, e, além disso, afirma que:

Desde 2013, a FIB tem tido um histórico pesaroso. Esta tem falhado em neutralizar qualquer dos quatro grupos armados contra os quais foi designada a lutar: as Forças Democráticas Aliadas (ADF), as Forças Democráticas pela Liberação de Ruanda (FDLR), a Força de Resistência Patriotica de Ituri (FRPI) e o Exército de Resistência do Senhor (LRA). De acordo com a ONU, essas milícias ainda retêm a capacidade de desestabilizar grande parte do leste da RDC e continuam a perpetrar ataques em comunidades locais (DAY, 2017, [S.I], tradução nossa) ${ }^{15}$.

Por outro lado, o relatório produzido pela EPON (Effectiveness of Peace Operations Network) sobre a MONUSCO tem posição intermediária sobre a efetividade da missão. Nesse sentido, o documento reconhece que a MONUSCO falhou em diversos aspectos, principalmente em erradicar os incidentes violentos em regiões específicas, como, por exemplo, Kisangani, Bukavu e Goma. No entanto, a EPON (2019, p. 115, tradução nossa) entende que também é preciso mudar o tipo de avaliação feita sobre tais operações, ou seja, "começar com o que elas têm alcançado em termos de prevenção de conflito, estabilidade e proteção, ao invés de colocar-lhes toda a culpa pelo o que não foram capazes em alcançar"16.

Desse modo, quando avaliado o papel da SANDF na Brigadas de Intervenção (FIB) contra o M23, o relatório que mede a efetividade da missão afirma que o desmantelamento desse grupo é um ponto de credibilidade da MONUSCO, e, além disso, há amplo consenso de que sem as operações da FIB, cuja protagonista é a SANDF, o número de mortos, estupros e de deslocados internos seria ainda maior (EPON, 2019).

Com base em tal avaliação, torna-se possível afirmar que a experiência dos soldados da África do Sul no terreno ratificou parcialmente a efetividade esperada dos militares nesse tipo de missão no pós-apartheid. Apesar das falhas apontadas acima, a SANDF foi responsável pela desarticulação do principal grupo guerrilheiro da região (M23), o que não deve ser desprezado no cálculo do sucesso de sua atuação.

\footnotetext{
15 No original: "since 2013, the FIB has had a dismal track record. It has failed to neutralize any of the other four armed groups it was tasked to fight: the Allied Democratic Forces (ADF), the Democratic Forces for Liberation of Rwanda (FDLR), the Front for the Patriotic Resistance in Ituri (FRPI) and the Lord's Resistance Army (LRA). According to the UN, these militias still retain the capacity to destabilize much of eastern DRC and continue to perpetrate attacks on local communities".

${ }_{16}$ No original: "start with what they have achieved in terms of conflict prevention, stability and protection, instead of putting all the blame on them for what they have not been able to achieve".
} 
Em se tratando de avaliar a eficiência dos militares sul-africanos na MONUSCO, direcionase a investigação para o critério de quão bem a Operação Mistral foi realizada. Dessa forma, a avaliação nessa seara está relacionada ao nível do desempenho dos militares e do uso de recursos no terreno.

Por meio da investigação feita, afirma-se que há profundas rachaduras no quesito eficiência dos militares da SANDF na RDC. Não apenas em questões orçamentárias, mas também na disciplina dos soldados, que pecam na otimização das operações realizadas pelo contingente sul-africano.

Antes de se analisar diretamente a atuação no terreno, vale frisar que a SANDF vem passando por um processo de sucateamento com as progressivas restrições orçamentárias do Departamento de Defesa. A Ministra Nosiviwe, em discurso proferido durante a votação do orçamento em defesa de 2018/19, alertou que os recursos destinados para a pasta estão tornando-se cada vez mais insustentáveis, e, além disso, afirma: "A África do Sul chegou ao ponto no qual esta deve tomar uma decisão sobre o tipo de Força de Defesa que deseja e pode sustentar” (MAPISA-NQAKULA, 2018, tradução nossa) ${ }^{17}$. Esse fato é consubstanciado nas palavras de Heinecken (2020, p. 35, tradução nossa), segundo a autora, "o orçamento de defesa para 2019/20 ajustado a 0,93\% do PIB significa uma continua redução real na alocação dos recursos e regressão no curso do tempo"18.

Diante dessa situação, o modo de gerência dos recursos destinados à MONUSCO vem tornando o quadro ainda mais delicado para as Forças Armadas da África do Sul. Em primeiro lugar, o financiamento da operação vem diretamente do orçamento do Departamento da Defesa, mediante posterior reembolso feito pela ONU. O problema é que a SANDF tem enfrentado profundas dificuldades em relação a restituição dos recursos despendidos no terreno. Como mostra Dean Wigrin (2017), o reembolso das despesas gastas pelo Departamento de Defesa com uniforme, salário, rações, acomodação, combustível, manutenção e logística eram feitos diretamente ao Tesouro Nacional da África do Sul até $2017^{19}$, levando à diluição das restituições nas diferentes pastas do governo.

Dessa forma, esse quadro fez com que as operações da SANDF na RDC gerassem prejuízos ao Departamento de Defesa, o qual não obteve por quase sete anos compensação financeira compatível com a quantidade dos recursos gastos, uma vez que as restituições eram distribuídas a outras pastas que nada tinham a ver com questões de Defesa.

Mesmo após a retificação de tal situação com a destinação completa do reembolso à pasta do Departamento de Defesa, a instituição ainda possui empecilhos que fazem da operação um prejuízo financeiro para as Forças Armadas. Além de erros burocráticos no preenchimento de requisições de

\footnotetext{
${ }^{17}$ No original: "South Africa has now reached the point where it must make a decision on the kind of Defence Force it wants and what it can afford".

${ }^{18}$ No original: with the defence budget for 2019/20 set at [...] o,93\% of GDP, this signifies a continued real reduction in budget allocation and regression over the course of time".

$19 \mathrm{O}$ reembolso dos gastos na MONUSCO passou a ser destinado diretamente ao Departamento de Defesa a partir de 2018.
} 
restituição financeira, o Departamento vem perdendo a capacidade de recuperar seus dispêndios monetários pela má condição dos equipamentos utilizados no terreno (WINGRIN, 2017).

É que a política de reembolso da ONU possui óbices a pagamentos de equipamentos utilizados que já não possuem boas condições de reuso ou reparo. Esse fato foi, inclusive, tema durante a visita da comissão parlamentar sul-africana nas instalações da SANDF na RDC. Segundo o relatório de tal visita, um dos desafios da missão definidos pelos parlamentares é de que o governo da África do Sul "deve substituir ou comprar novos equipamentos para a qualificação do reembolso completo na área da missão” (ÁFRICA DO SUL, 2018b, tradução nossa) ${ }^{20}$. Os fatos acima delineados indicam que a operação na RDC não cumpre os requisitos de eficiência nas relações civis-militares, pois caso não houvesse problemas nos reembolsos ao Departamento de Defesa, os custos de manutenção da SANDF no terreno seriam menores.

Outro fator que influencia na diminuição da eficiência da atuação da SANDF na MONUSCO são os casos de indisciplina entre os soldados. Em 2015, por exemplo, mais de 43 militares foram excluídos da missão por violarem o toque de recolher estabelecido pelo código de conduta da Organização das Nações Unidas (IOL, 2018). Já no ano de 2017, um soldado sul-africano assassinou sua companheira, também integrante da SANDF, no batalhão da Brigada de Intervenção que estavam alocados em Goma (CHAMBERS, 2018). Além desses exemplos, os casos que ganham destaque são as denúncias de assédio e abuso sexual por parte dos soldados sul-africanos. No ano de 2013, Mangwanda informa que (2017, p. 27, tradução nossa): “[...] alguns membros da Força Nacional de Defesa da África do Sul (SANDF) servindo na MONUSCO foram alegadamente absolvidos de 93 casos de má-conduta, 23 dos quais sendo de estupro, exploração sexual e abuso sexual de mulheres congolesas" ${ }^{21}$.

Esse quadro reincide nos anos posteriores. De acordo com um dos principais portais de notícias sobre defesa em África, o contingente da SANDF estava sendo investigado por cinco casos de exploração sexual e abuso (SEA), que aconteceram entre o ano de 2014 a 2016 na RDC, sendo um deles com vítima menor de idade (DEFENCEWEB, 2018).

Não obstante, o número de denúncias desse tipo de violação de conduta extrapola os cinco casos investigados. Sete casos de SEA foram reportados entre os anos de 2015 e 2016. Já no período de 2017 e 2018, essa quantidade subiu para 13 (DEFENCEWEB, 2018).

Os dados trazidos por Jika e Saba (2019) são ainda mais graves. Segundo tais autores, os casos de SEA por parte da SANDF na RDC chegaram à soma de 21 casos até novembro de 2019, os quais incluem alegações de sexo transacional, relações exploratórias e estupro.

${ }^{20}$ No original: "should replace or purchase new equipment to qualify for a full reimbursement in the Mission Area".

${ }^{21}$ No original: "some members of the South Africa National Defence Force (SANDF) serving under MONUSCO were allegedly acquitted of 93 cases of misconduct, 23 of these cases being of rape, sexual exploitation and sexual abuse of Congolese women". 
Tais casos de indisciplina tensionam o controle sobre os militares, apesar de tais violações terem sido condenadas, investigadas e punidas pelo Departamento de Defesa. Esses exemplos, além de diminuírem o grau de eficiência da missão, impactarem na reputação da corporação e gerarem custos para o Estado da África do Sul com repatriamento de soldados, abertura de inquéritos, investigações e processos nas cortes marciais; melindram os esforços de monitoramento que têm sido exercidos pelo Estado sul-africano para garantir o controle, como será visto a seguir.

\subsection{MECANISMOS DE MONITORAMENTO E SUAS CONTRIBUIÇÕES PARA O CONTROLE FORMAL E INFORMAL}

Antes de abordamos os mecanismos de monitoramento sobre a atuação da SANDF na MONUSCO $^{22}$, vale frisar que a supervisão política sobre as Forças Armadas possui caráter multidimensional, abrangendo uma ampla miríade de mecanismos.

Dentre tais mecanismos, podem-se elencar o Ministério da Defesa e comitês parlamentares como instrumentos institucionais de controle. Nesse sentido, pressupõe-se que essas instituições possuam responsabilidade sobre as normas profissionais, orçamento e avaliação do desempenho dos militares (BRUNEAU E MATEI, 2008) para que haja uma base sólida de monitoramento nas relações civis-militares.

No que concerne à atuação da SANDF na MONUSCO, é possível identificar a existência de tais mecanismos formais garantidores da vigilância política. Isso não quer dizer que a experiência no terreno tenha sanado todas as necessidades de um controle eficaz sobre os militares na África do Sul, tendo em vista a reincidência dos casos de indisciplina no terreno; mas também é impreciso afirmar que elementos formais de supervisão da SANDF na República Democrática do Congo foram insignificantes para a cimentação dos anseios civis sobre a atuação dos militares na era pósapartheid.

O primeiro elemento de análise do monitoramento parte da instituição do Executivo responsável pelas Forças Armadas, o Departamento de Defesa. Desde a promulgação da Constituição de 1996, a chefia do Estado Maior tem sido legalmente subordinada a essa instituição, com exceção em tempos de guerra, quando fica sob a responsabilidade direta do Presidente da República. Segundo a Carta Magna de 1996, o ministro da defesa é encarregado de prestar contas das atividades militares ao Congresso e ao gabinete presidencial (HEINECKEN, 2020); e é por meio dessas

\footnotetext{
${ }^{22}$ Segundo Lindy Heinecken (2020), a grande contribuição sul-africana para a MONUSCO, com cerca de 1300 militares, concentra-se na Operação Mistral. No entanto, há mais duas operações na RDC: Operação Teutonic, com uma pequena quantidade de soldados empenhados em reconstruir o exército congolês; e o Projeto Thebe, com 11 militares sul-africanos responsáveis por treinar batalhões de reação rápida da RDC. Para fins desta pesquisa, a investigação da atuação da SANDF na MONUSCO se restringirá à Operação Mistral por meio da Brigada de Intervenção.
} 
prerrogativas constitucionais que o Departamento de Defesa exerce o controle sobre a atuação da MONUSCO na RDC.

Como ponto de partida, pode-se citar a visita da Ministra da Defesa Nosiviwe-Nqakula ao contingente da SANDF em Goma, na República Democrática do Congo em 2017; esse exemplo simboliza a supervisão do Departamento de Defesa sobre a Operação Mistral na MONUSCO. O propósito de tal viagem foi de monitoramento das atividades da brigada no terreno, como, por exemplo, avaliação do impacto negativo e positivo das operações e a condição da tropa feminina na missão (DEFENCE WEB, 2017).

Além da visita à missão, o controle institucional do Departamento de Defesa também se concretiza na constante vigilância da referida ministra sobre questões envolvendo assédio sexual por parte de soldados sul-africanos na RDC.

Na revista onusiana Africa Renewal, ao ser tratada a questão dos abusos sexuais causados pelos efetivos da SANDF no exercício da MONUSCO, a ministra responde ter tolerância zero para essas práticas, afirmando que cortes marciais foram estabelecidas no terreno para julgar casos de tal natureza (IGHOBOR, 2019).

Em discurso proferido na base militar de Brug em 2017, Nosiviwe-Nqakula também demonstra empenho em manter a disciplina dos soldados na MONUSCO para que sua atuação continue de acordo com os anseios civis de Pretória. Nesse sentido, Nqakula (2017, p.2, tradução nossa) afirma que o caso de abuso sexual no Estado da República Democrática do Congo “[...] clama aos comandantes que assegurem a execução da disciplina, e nós estamos levando essa questão muito a sério... a um ponto de colocar emendas extensivas ao Código de Disciplina Militar"23. Além disso, a ministra reitera em seu discurso o imperativo da supremacia civil sobre os militares e a importância do cumprimento das normas profissionais:

[...] vocês devem rededicar-se a sua missão e aos seus valores profissionais de acordo com o nosso Código de Conduta. Vocês precisam assegurar que estão se esforçando consistentemente para merecer a confiança que o povo de nosso país e de qualquer lugar além de nossas fronteiras que estiverem empregados lhes ofereceram. [...] Vocês têm grandes expectativas a suprir. Portanto, garantam que sempre estejam levando a cabo suas tarefas dentro do Quadro de normas e valores da profissão military (ÁFRICA DO SUL: Ministra da Defesa e Militares Veteranos - Nosiviwe Mapisa-Nqakula, p. 3, 2017, tradução nossa). ${ }^{24}$

\footnotetext{
${ }^{23}$ No original: "[...] calls upon commanders to ensure that there is discipline enforced, and we are taking this matter very seriously... to a point of tabling extensive amendments to the Military Discipline Bill during this year".

${ }_{24}$ No original: "[...] you must rededicate yourselves to your declared professional mission and values as encapsulated in our Code of Conduct. You need to ensure that you consistently strive to deserve the trust which the people of our country and wherever you are deployed beyond our borders granted you. [...] You have big shoes to fill. Therefore ensure that you carry out your tasks at all times within the framework of the norms and values of the military profession [...]".
} 
Outro ponto que pavimenta a fiscalização do Departamento da Defesa sobre os militares nessa seara foi a instalação de uma força tarefa ministerial para investigar as ocorrências de abuso sexual na RDC, que estabeleceu uma linha direta de denúncia para infrações de tal natureza na SANDF (GERBER, 2019).

No entanto, a vigilância sobre os militares vai além das questões expostas acima. Como já foi mencionado, é responsabilidade do Departamento da Defesa prestar informações da atuação da SANDF no terreno. Tais informações materializam-se nas publicações da revista oficial da instituição "South African Soldier", a qual vem sendo publicada desde 2003, abordando as diferentes atividades realizadas pelos militares da África do Sul.

Desse modo, as operações da SANDF na República Democrática do Congo aparecem frequentemente nas edições da revista, embora de maneira difusa. Analisando suas publicações mais recentes, afirma-se que a abordagem da MONUSCO nesse instrumento do Departamento de Defesa contribui para o controle civil sobre os militares ao dar maior transparência às atividades dos soldados no terreno da RDC.

Na edição "Republic of South Africa Peace Missions", as operações dos militares sulafricanos na Brigada de Intervenção (FIB) ${ }^{25}$ são exploradas na entrevista do tenente-coronel Andries Matlaila, o qual explica os propósitos e ações da SANDF na RDC. De acordo com o militar, as operações de combate no terreno servem à proteção de civis, apoio ao governo e monitoramento do embargo de armas; e, naquele momento, os soldados sul-africanos estavam agindo em conjunto com Kinshasa contra grupos rebeldes nos arredores de Beni, Kamango e Irimu (TLHAOLE, 2017, p. 20).

Ainda sobre a atuação da SANDF no terreno, a edição "SANDF marks 20 years in Peace Missions" traz o artigo do Sargento Tlhaole (2019), o qual pormenoriza as operações da FIB contra o grupo rebelde tutsi M23. O autor informa que a SANDF atuou na região de Kabalo por meio do helicóptero de combate sul-africano Rooiavalk, com o qual foram disparados mísseis de 20mm e $70 m m$ contra abrigos do M23 próximos a território ruandês.

Além de pôr as operações táticas do contingente sul-africano na MONUSCO em evidência, a South African Soldier elucida alguns mecanismos de controle da atuação de seus soldados, como, por exemplo, o artigo de Obed Medupe (2019), o qual detalha a visita de Mami Mizotori, representante especial da ONU, ao palco das operações. Segundo o autor, Mizotori reuniu-se com os comandantes do contingente da FIB e recebeu informações sobre a situação de segurança e as operações em andamento no terreno.

A edição "SA Peacekeepers in the DRC" relata a importante visita parlamentar aos peacekeepers na República Democrática do Congo. Nas palavras de Thaole (2018, p. 14, tradução nossa), "o objetivo da visita foi de examiner as condições sob as quais as forças sul-africanas operam

\footnotetext{
25 A Brigada de Intervenção, composta pela Tanzânia, Malaui e África do Sul, é um mecanismo de peace enforcement baseado no capítulo VII da Carta da Organização das Nações Unidas. Instalada na MONUSCO em 2013, o propósito da Brigada de Intervenção é de conduzir operações ofensivas contra grupos armados que atentam contra civis no leste da RDC (CAMMAERT; BLITH, 2013).
} 
na RDC" ${ }^{26}$. Nessa questão, os comitês parlamentares em defesa foram ao encontro de várias instalações da SADF, como, por exemplo, o contingente em Kinshasa, o esquadrão de aviação em Goma, a Brigada de Intervenção em Erengeti e a Companhia de Base de Operação em Beni. Durante a passagem por tais locais, o presidente da comissão parlamentar, Stanley Motimele, reconheceu os avanços da SANDF contra grupos rebeldes, apesar de ter expressado preocupação com os casos de indisciplina de alguns soldados na missão (TLHAOLE, 2018).

Os exemplos apresentados acima não esgotam os casos em que a atuação da SANDF na MONUSCO foi tratada pela revista. Dessa forma, acredita-se que esse tipo de provimento de informação é um instrumento que, embora insuficiente se tratado de maneira isolada, contribui para o controle nas relações civis-militares; pois a frequência desses relatos demonstra que o Departamento de Defesa permanece a par dos desdobramentos e da atuação das Forças Armadas na operação de paz, dando condições para a solidificação dos anseios da classe política sobre os miliares na África do Sul pós-apartheid.

Mas o monitoramento não se deve restringir a tal órgão do Poder Executivo, como assinalam Bruneau e Matei (2008). No caso da África do Sul pós-apartheid, a reforma do setor de segurança incluiu o Parlamento como ferramenta de controle nas relações civis-militares por meio do Comitê Misto Permanente em Defesa (JSCD).

Como assinala Heinecken (2020), esse comitê é composto por parlamentares da Assembleia Nacional e do Conselho Nacional de Províncias, tendo a função de investigar e fazer recomendações sobre assuntos que envolvem as forças sul-africanas, como, por exemplo, organização, orçamento, supervisão das operações e política de defesa. No que concerne à atuação da SANDF na MONUSCO (Operação Mistral), o Comitê tem-se engajado em diferentes maneiras no controle dessa operação.

A título de exemplo, cita-se a reunião da SANDF com o JSCD e o Departamento de Relações Internacionais e Cooperação em março de 2018, na qual diversos aspectos da operação Mistral foram apresentados aos parlamentares (Figura 1), como objetivos da missão, equipamentos utilizados, disciplina dos soldados e financiamento das operações.

Na ocasião, os parlamentares levantaram preocupação com os casos de exploração sexual no mandato da MONUSCO, recomendando que os soldados não permanecessem mais que três meses na missão para evitar o distanciamento prolongado de seus laços afetivos, o que aumentaria os riscos de envolvimento do contingente sul-africano com a população civil no terreno.

Além disso, a falta de financiamento das operações aéreas por parte da Organização das Nações Unidas foi questionada e ressaltou-se a necessidade de reembolso dos gastos em tais atividades aos cofres sul-africanos (ÁFRICA DO SUL, 2018a).

\footnotetext{
${ }^{26}$ No original: "the aim of the visit was to examine the conditions under which [south-african] forces operate
} in the DRC". 


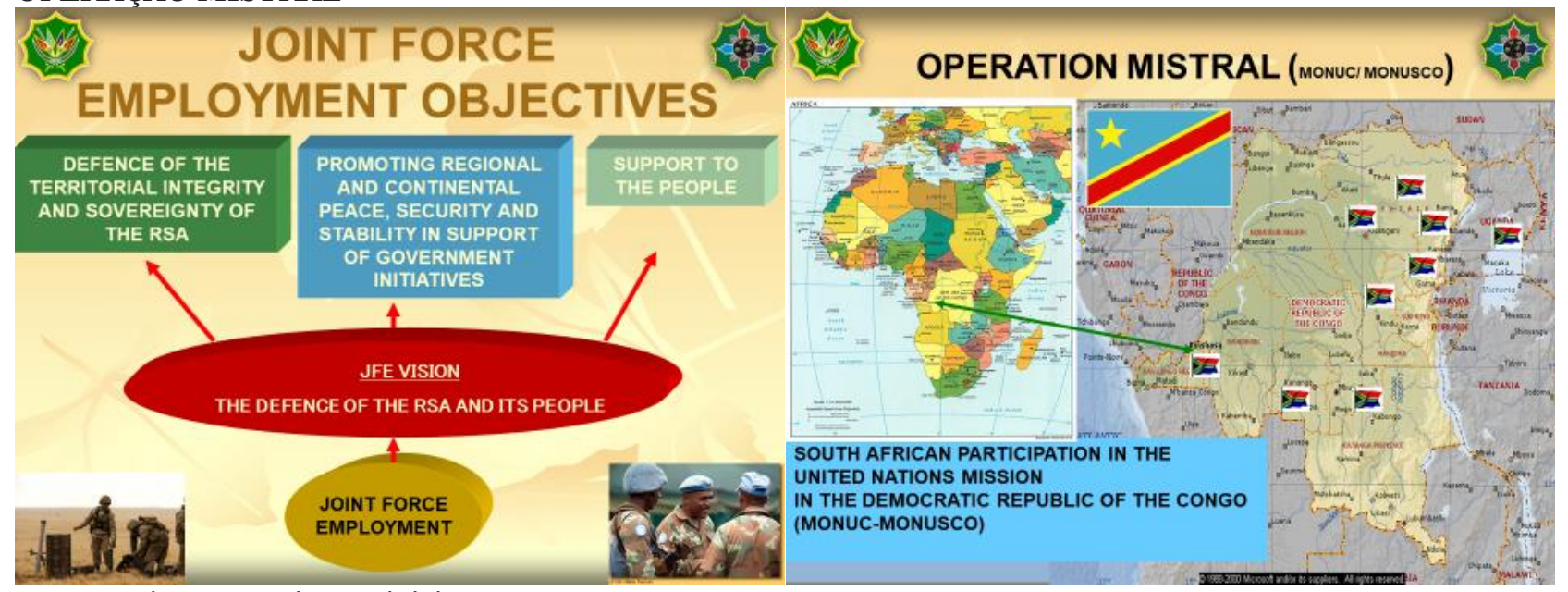

Fonte: Joint Operations Division, $2018^{27}$.

Uma segunda demonstração de como a experiência da Operação Mistral é um instrumento prático na ratificação do monitoramento político sobre os miliares traduz-se no relatório produzido pela JSCD em relação à visita parlamentar na República Democrática do Congo em 2018. Segundo o relatório, a visita de supervisão:

[...] permitiu aos membros do Parlamento ganhar visão das circunstâncias do emprego das tropas, como também serem informados em conquistas e desafios operacionais. Durante o processo, a Delegação foi atualizada sobre assuntos específicos, como reembolso pela Organização das Nações Unidas pelos serviços executados, questões logísticas relacionadas à aquisição e transporte de ida e volta da área da missão, os casos de denúncia de abuso e exploração sexual (SEA) e as contribuições da missão para a Missão das Nações Unidas na República Democrática do Congo (MONUSCO), em particular, a Brigada de Intervenção (FIB). ${ }^{28}$

O documento também traz informações pormenorizadas das atividades realizadas em todos os locais nos quais a visita técnica passou, como, por exemplo, no contingente da SANDF em Kinshasa, onde os parlamentares foram informados sobre as operações do batalhão, a situação política no local, os desafios e conquistas da operação. Recebidos pelo Tenente-Coronel Molusi, a delegação inteirou-se das reivindicações dos soldados pela renovação de uniforme, alteração na política de partida da missão e substituição de equipamentos (ÁFRICA DO SUL, 2018b).

Já em visita à base aérea da SANDF em Goma, o Comitê foi informado nos problemas logísticos da missão que levaram à falta de armamentos e peças de reposição dos helicópteros de combate Oryx e Rooivalk, diminuindo as horas totais de voo da aeronáutica sul-africana sobre o

\footnotetext{
${ }_{27}$ Disponível em: <https://pmg.org.za/committee-meeting/25896>. Acesso em: 21/o1/2020.

${ }_{28}$ No original: "[...] allowed Members of Parliament to gain insight into the circumstances of deployment as well as to be briefed on operational achievements and challenges. In the process the Delegation was updated on specific issues such as the reimbursements by the United Nations for services rendered, logistical issues related to procurement and transportation to and from the Mission Area, the reported Sexual Exploitation and Abuse (SEA) cases, and its contribution to the United Nations Organisation Stabilisation Mission in the Democratic Republic of the Congo (MONUSCO), in particular the Force Intervention Brigade (FIB)."
} 
território de operação (ÁFRICA DO SUL, 2018b). No fim do relatório, o Comitê define recomendações a serem tomadas pelo Departamento de Defesa para superação dos desafios da Operação Mistral.

Destarte, as operações da SANDF na RDC contribuíram para a concretização parcial do controle formal sobre as Forças Armadas, uma vez que representa um importante marco no exercício prático de supervisão aos soldados e ganho de experiência nos assuntos militares por parte dos parlamentares, estreitando o espaço existente entre a classe política e militar.

Constatado o impacto positivo da MONUSCO sobre os mecanismos formais de vigilância por meio dos poderes Executivo e Legislativo, convém agora fazer algumas considerações sobre os mecanismos informais de monitoramento, que extravasam as fronteiras da classe política, atingindo a opinião pública e a mídia.

De antemão, afirma-se que há dificuldades em comensurar o impacto da missão da SANDF na RDC nesse espectro. No entanto, há evidências de que a Operação Mistral pouco contribuiu para o exercício da supervisão não formal nas relações civis-militares na África do Sul, onde há o progressivo desinteresse e desconhecimento civil sobre os assuntos relacionados à SANDF (HEINECKEN, 2020).

Quando se analisam os principais jornais em circulação de língua inglesa no país, é possível notar o baixo interesse da mídia pela MONUSCO e, em específico, o diminuto impacto da Operação Mistral na atenção do público.

A tabela 1 mostra a quantidade de reportagens e notícias que tratam da atuação da SANDF na RDC (MONUSCO e Operação Mistral), revelando seu aspecto insignificante quando comparada a outros assuntos tratados pela mídia relacionados às Forças Armadas da África do Sul. Ademais, as pouquíssimas manchetes que tratam sobre a Mistral em específico não abordam diretamente as operações e desdobramentos no terreno, mas apenas os casos de denúncia de exploração sexual por parte dos soldados sul-africanos.

Desse modo, a avaliação que se faz dos números obtidos é de que a atuação na MONUSCO teve baixíssimo impacto no interesse do público, e, consequentemente, pouco contribuiu para a consolidação do controle informal nas relações civis-militares na África do Sul. Tal resultado pode relacionar-se com o argumento de Heinecken (2011, p. 134, tradução nossa), de que a opinião pública é "menos preocupada com segurança externa e mais com ameaças à segurança interna, como crime, tráfico de drogas e resposta a desastres”29.

\footnotetext{
29 No original: "less concerned with external security, and more with internal security threats such as crime,
} drug trafficking and disaster relief". 
TABELA 1 - QUANTITATIVO DE RESULTADOS DE BUSCA DOS TERMOS SANDF, MONUSCO E MISTRAL NOS SITES DOS PRINCIPAIS JORNAIS EM CIRCULAÇÃO DE LÍNGUA INGLESA NA ÁFRICA DO SUL (2018-2020)30

\begin{tabular}{l|l|l|l}
\hline Jornal Pesquisado & SANDF & MONUSCO & MISTRAL \\
\hline Daily Sun & 69 & 1 & 0 \\
\hline The Star & 615 & 17 & 2 \\
\hline Sowetan & 123 & 9 & $0^{31}$ \\
\hline The Citizen ${ }^{2}$ & 36 & 5 & 1 \\
\hline
\end{tabular}

Fonte: Elaboração própria com base nos dados da pesquisa33.

Não obstante, essa vedação da opinião pública às operações da Operação Mistral é agravada pela disposição limitada da classe política em tratar o assunto com o setor civil, o que pode ser observado no Relatório Anual do Departamento de Defesa (2018).

É que tal documento delineia as atividades das Forças Armadas no decorrer de cada ano e fazem uma avaliação se os objetivos almejados pela classe política foram alcançados pelos militares. Nessa seara, a seção desse documento que dispõe do status da performance da SANDF na MONUSCO aparece como informação confidencial.

Por meio do que foi discutido até aqui, afirma-se, então, que a atuação da SANDF na MONUSCO contribuiu expressivamente na pavimentação da vigilância formal sobre os militares34; em relação ao monitoramento informal, não há evidências sólidas de que a atuação da SANDF na RDC tenha fortalecido a atenção pública aos assuntos militares, ainda que os dados quantitativos coletados sejam incipientes e mereçam ser tratados como uma sondagem inicial.

Convém ressaltar que tais mecanismos de monitoramento, apesar de serem requisitos para ratificação do controle sobre os militares, não são suficientes por si só. Como visto na seção anterior, a eficiência maculada dos militares sul-africanos na MONUSCO vai de encontro aos esforços formais de supervisão de Pretória. É que eficiência, efetividade e controle existem em simbiose e a rachadura em um desses elementos coloca em questão o funcionamento dos demais. Bruneau e Croissant (2019) ressaltam que o controle íntegro dos civis sobre os militares se baseia não apenas em monitorar, mas também em governar efetivamente a instituição armada.

\footnotetext{
${ }^{30}$ A escolha dos jornais baseou-se no ranking do Bureau de Circulação da África do Sul. Dados disponíveis em: <http://www.marklives.com/2018/05/abc-analysis-q1-2018-the-biggest-circulating-newspapers-in-sa/>. Acesso em: 10/02/2020.

${ }^{31}$ Resultados obtidos com o termo "Mistral" não possuem qualquer relação com a operação militar.

32 Apenas os resultados de 2019 e 2020 foram contados (quantitativo de 2018 indisponíveis).

33 Dados extraídos nos seguintes sítios: Daily Sun, <https://www.dailysun.co.za/>; The Citizen $<$ https://citizen.co.za/>; The Star, <https://www.iol.co.za/news $>$; $\quad$ Sowetan $<$ https://www.sowetanlive.co.za/>, acesso em: 10/02/2020. Sem prejuízo para os argumentos deste artigo, os dados estão sujeitos a variação de acordo com alterações realizadas nos sites pesquisados após a data de acesso. 34 É válido questionar se os casos de assédio sexual não representariam a falha dos mecanismos de monitoramento sobre os militares sul-africanos na RDC. No entanto, afirma-se que a reação parlamentar e as providências tomadas pelo Departamento de Defesa frente a tal questão demonstram que esse elemento de controle civil sobre a SANDF não ignorou a ocorrência de violações de conduta no terreno, tratando o caso com seriedade. Cabe investigar se a conduta errônea, mesmo após repressão do Estado, ainda continuará a ser uma realidade na SANDF, o que demonstrará a falha em tal espectro de controle formal.
} 
Além disso, Bland (1999) pontua que um aspecto crítico das relações civis-militares envolve a manutenção da disciplina dos soldados, uma vez que soldados indisciplinados são nefastos para a sociedade. Nesse sentido, os atos nocivos praticados contra a população congolesa durante o exercício da MONUSCO por parte de alguns militares sul-africanos representam um sinal de alerta para o controle civil, uma vez que estes passam a colocar em risco a própria sociedade que supostamente os soldados deveriam proteger. Tais práticas podem ser internalizadas pelo corpo militar, o qual, caso venha a ser chamado para atuar em território doméstico, pode se tornar um problema direto para os civis da África do Sul.

É que o controle civil sobre os militares pressupõe, além dos mecanismos formais de controle sobre a instituição armada (hardware), a existência de crenças, atitudes, princípios e normas a nível individual por parte dos militares (software) (BLAND, 2001). Portanto, é importante garantir "que esse ‘corpo de disciplina armado’ se comporte de maneira que salvaguarde o Estado sem trazer danos aos governos e cidadãos pela indisciplina e desventuras (BLAND, 1999, p. 13, tradução nossa)35. Essa situação insere Pretória em um impasse, no qual os mecanismos de supervisão sobre a SANDF na MONUSCO cimentam o controle sobre os militares ao mesmo tempo em que a má eficiência dos soldados no terreno enfraquece tal ganho de experiência.

\section{CONSIDERAÇÕES FINAIS}

A título de conclusão, é possível responder ao objetivo de pesquisa colocado. Como foi visto ao longo do trabalho, apesar de ter parcialmente contribuído para a consolidação dos anseios civis em relação à efetividade e ao controle dos militares por meio dos mecanismos formais de monitoramento, a experiência da SANDF na MONUSCO tem gerado impacto negativo para a ratificação da eficiência, a qual tem, consequentemente, enfraquecido os ganhos advindos dos esforços de supervisão de Pretória sobre os militares na África do Sul pós-apartheid, colocando o Estado em uma situação de dubiedade em relação ao efetivo controle civil.

Dessa forma, meios de retificação das deficiências apontadas devem ser investigados. A possibilidade de melhor garantir o monitoramento informal poderia ser alcançada se o Departamento de Defesa fornecesse mais informações sobre a missão em seu Relatório Anual à sociedade civil. Além disso, o contato direto da mídia com os militares também pode ser um caminho para contribuir em maior divulgação dos desdobramentos da missão.

Para o melhoramento da efetividade e eficiência da missão, a maior destinação orçamentária ao Departamento de Defesa aumentaria capacidade de treinamento de recursos humanos e de aquisição de novos equipamentos, sendo um caminho para dirimir os casos de indisciplina no

35 No original: "that this 'armed disciplined body' behaves in ways that safeguard the state without bringing harm through indiscipline, misadventure [...] to governments or citizens". 
terreno e as dificuldades de obtenção de reembolso pela ONU. Além disso, como já prescreveu Ngoma (2006), a incorporação de elementos de cidadania por meio de uma educação cívica poderia evitar situações de abusos cometidas contra civis no terreno. Tais recomendações clamam por prudência e devem ser ponderadas e bem planejadas antes de postas em prática.

O fato é que, apesar das vicissitudes, a missão da SANDF na RDC tem potencial em ser um importante instrumento de consolidação dos anseios civis em relação aos militares na era pósapartheid. Apesar das deficiências discutidas, o papel da MONUSCO para a harmonização das relações civis-militares da África do Sul não deve ser desprezado, cabendo ao Estado e a sociedade sul-africana melhor aproveitar essa oportunidade; e isso só irá ocorrer caso pontos frágeis apontados neste trabalho sejam retificados.

*Artigo recebido em 06 de setembro de 2020, aprovado em 08 de fevereiro de 2021.

\section{REFERÊNCIAS}

ÁFRICA DO SUL. Comitê Misto Permanente em Defesa. Grupo de Monitoramento Parlamentar. International peacekeeping operations: SANDF \& DIRCO briefing. 2018. Disponível em: <https://pmg.org.za/committee-meeting/25896/>. Acesso em: 02 fev. 2020.

ÁFRICA DO SUL. Comitê Misto Permanente em Defesa. Grupo de Monitoramento Parlamentar. Report of the joint oversight visit of the Joint Standing Committee on Defence and the Portfolio Committee on Defence and Military Veterans to Kinshasa and Goma in the Democratic Republic of the Congo from 25 to 29 March 2018, dated 9 April 2018. 2018. Relatório. Disponível em: https://pmg.org.za/tabled-committee-report/3474/. Acesso em: 18 fev. 2020.

ÁFRICA DO SUL. DEPARTAMENTO DE DEFESA DA ÁFRICA DO SUL. South African Defence Review. Pretória: Governo da África do Sul, 1998. Disponível em: <https://www.gov.za/sites/default/files/gcis_document/201409/defence-review1998.pdf>. Acesso em: 15 fev. 2020.

ÁFRICA DO SUL. DEPARTAMENTO DE DEFESA DA ÁFRICA DO SUL. South African Defence Review. Pretória: Governo da África do Sul, 2015. Disponível em: <http://pmg-assets.s3-websiteeu-west-1.amazonaws.com/170512review.pdf>. Acesso em: 15 fev. 2020.

ÁFRICA DO SUL. Ministra da Defesa e Militares Veteranos: (2012-2020: Nosiviwe MapisaNqakula). Minister Mapisa-Nqakula speaking notes on the occasion of international peacekeepers' day, $29^{\text {th }}$ may 2017 at Bridge to Operations, De Brug Military Base. Bloemfontein, 29 mai. 2017. 4 f. $\quad$ Disponível $\quad$ em: $<$ http://www.dod.mil.za/media/media2017/INTERNATIONAL\%20PEACEKEEPERS'\%20DAY.pdf >>. Acesso: 22 fev. 2020

BLAND, Douglas L.. A Unified Theory Of Civil-Military Relations. Armed Forces \& Society, [S.L.], v. 26, n. 1, p. 7-25, out. 1999. SAGE Publications. 
BLAND, Douglas L.. Patterns in Liberal Democratic Civil-Military Relations. Armed Forces \& Society, [S.L.], v. 27, n. 4, p. 525-540, jul. 2001

BRUNEAU, Thomas C.; CROISSANT, Aurel. Civil-Military Relations: Why Control Is Not Enoguh. In: BRUNEAU, Thomas C.; CROISSANT, Aurel (Ed.). Civil-Military Relations: Control and Effectiveness Across Regimes. Londres: Lynne Rienner, 2019. Cap. 1. p. 1-19.

BRUNEAU, Thomas C.; MATEI, Florina Cristiana (cris). Towards a New Conceptualization of Democratization and Civil-Military Relations. Democratization, [s.l.], v. 15, n. 5, p.909-929, dez. 2008.

CALLINICOS, Alex. South Africa: End of Apartheid and After. Economic And Political Weekly, Mumbai, v. 29, n. 36, p.2355-2363, 3 set. 1994 . Disponível em: <https://www.epw.in/journal/1994/36/special-articles/south-africa-end-apartheid-andafter.html>. Acesso em: 15 fev. 2020.

CAMMAERT, Major General Patrick; BLITH, Fyona. The UN Intervention Brigade in the Democratic Republic of the Congo. Issue Brief, Nova York, v. 1, n. 1, p.1-13, jul. 2013. Disponível em: <https://www.ipinst.org/wpcontent/uploads/publications/ipi_e_pub_un_intervention_brigade_rev.pdf $>$. Acesso em: 28 jan. 2020.

CHAMBERS, Dave. SANDF soldier who murdered girlfriend in DRC loses appeal. 2018. Times Live. Disponível em: https://www.timeslive.co.za/news/south-africa/2018-10-03-sandfsoldier-who-murdered-girlfriend-in-drc-loses-appeal/. Acesso em: 18 fev. 2020.

DAY, Adam. The Best Defence Is No Offence: Why Cuts to UN Troops in Congo Could Be a Good Thing. United Nations University Articles, Nova York, maio 2017. Disponível em: https://unu.edu/publications/articles/why-cuts-to-un-troops-in-congo-could-be-good-thing.html. Acesso em: 10 fev. 2020.

DEFENCE WEB. Defence Minister in the DRC. 2017. Disponível em:<< https://www.defenceweb.co.za/joint/diplomacy-a-peace/defence-minister-in-the-drc/>> Acesso em: 30 jun. 2020.

DEFENCE WEB.SANDF investigating sexual misconduct by SA soldiers in the DRC. 2018. Disponível em: https://www.defenceweb.co.za/sa-defence/sa-defence-sadefence/sandf-investigating-sexual-misconduct-by-sa-soldiers-in-the-drc/. Acesso em: 25 fev. 2020.

Departamento de Defesa. Annual Report. Pretória: Departamento de Defesa, 2019. 394 p. Disponível em: http://www.dod.mil.za/documents/annualreports/DOD\%20Annual\%20Report\%20for\%20FY201 8-19\%20(FINAL\%20Web\%20Layout).pdf. Acesso em: 19 fev. 2020.

EFFECTIVENESS OF PEACE OPERATIONS NETWORK - EPON (Noruega) (ed.). Assessing the Effectiveness: of the united Nations Mission in the DRC/MONUC -MONUSO. Oslo: Norwegian Institute Of International Affairs, 2019. 129 p. Disponível em: https://reliefweb.int/sites/reliefweb.int/files/resources/Assessing-the-effectiveness-of-theUnited-Nations-Mission-in-the-DRC-MONUC-\%E2\%80\%93-MONUSCO.pdf. Acesso em: 23 fev. 2020.

FRANKEL, Philip. Smoke and Mirrors: Transforming the Armed Forces. In: FRANKEL, Philip. Soldiers in a Storm: The Armed Forces in South Africa's Democratic Transition. Boulder: Westview, 2000. cap. 3, p. 101-146. 
GERBER, Jan. Sexual exploitation and abuse in SANDF: Task team to investigate cases dating back to 2014. News24. [s.l.], dez. 2019. Disponível em: <https://www.news24.com/SouthAfrica/News/sexual-exploitation-and-abuse-in-sandf-taskteam-to-investigate-cases-dating-back-to-2014-20191202>. Acesso em: 23 fev. 2020.

GIL, Antônio Carlos. Como elaborar projetos de pesquisa. 4. ed. São Paulo: Atlas, 2008.

HEINECKEN, Lindy. South Africa's post apartheid: Lost in Transition and Transformation. Gewerbestrasse: Springer, 2020.181 p.

HEINECKEN, Lindy. DEFENCE, DEMOCRACY AND SOUTH AFRICA'S CIVIL-MILITARY GAP. Scientia Militaria - South African Journal Of Military Studies, [s.l.], v. 33, n. 1, p.119140, 26 jul. 2011. Stellenbosch University.

HUNTINGTON, Samuel P. The Soldier and the State: The Theory and Politics of Civil-Military Relations. Cambridge, Eua e Londres: The Belknap Press Of Harvard University Press, 2000. 534 p. $15^{\mathrm{a}}$ impressão.

IGHOBOR, Kingsley. Reshaping the forces: Nosiviwe Mapisa-Nqakula. Africa Renewal. [s.i], p. 26-27. ago. 2019. Disponível em: <https://www.un.org/africarenewal/magazine/august-november2019/reshaping-forces>. Acesso em: 22 fev. 2020.

IOL (África do Sul). 43 SANDF members dismissed for misconduct. 2018. Disponível em: https://www.iol.co.za/thepost/43-sandf-members-dismissed-for-misconduct-17368758. Acesso em: 28 fev. 2020.

JANOWITZ, Morris. The Professional Soldier: A Social and Political Portrait. Nova York: Free Press, 2017. 464 p.

MANGWANDA, Mylène Lusegu. A cry for justice: the lack of accountability for perpetrators of sexual violence against women in the Democratic Republic of Congo. 2017. 93 f. Tese (Mestrado) Curso de Filosofia, Universidade de Pretória, Pretória, 2017. Disponível em: https://repository.up.ac.za/handle/2263/64622. Acesso em: 14 fev.2020.

MASHIKE, Lephophotho. 'Blacks can Win Everything, but the Army': the transformation of the south african military between 1994 and 2004. Journal Of Southern African Studies, [S.L.], v. 33, n. 3, p. 601-618, set. 2007. Informa UK Limited.

MATEI, Florina Cristiana. A new conceptualization of civil-military relations. In: BRUNEAU, Thomas; MATEI, Fiorina Cristiana. The Routledge Handbook of Civil-Military Relations. [abingdon]: Routledge, 2012. p. 26-38.

MAPISA-NQAKULA, Nosiviwe. Minister Nosiviwe Mapisa-Nqakula: Defence Dept Budget Vote 2018/19. 2018. Discurso. Disponível em: https://www.gov.za/speeches/minister-nosiviwemapisa-nqakula-defence-dept-budget-vote-201819-18-may-2018-oooo. Acesso em: 27 fev. 2020.

MAPISA-NQAKULA, Nosiviwe. Media statement by the Minister of Defence, Ms Nosiviwe Mapisa-Nqakula during the peacekeeping and post conflict reconstruction and development media briefing. 2014. Discurso. Disponível em: https://www.gov.za/mediastatement-minister-defence-ms-nosiviwe-mapisa-nqakula-during-peacekeeping-and-post-conflict. Acesso em: 22 fev. 202.

MEDUPE, Tenente Obed. The Force Intervention Brigade Commander receives the United Nations Special Representative to his area of responsibility. South African Soldier, Pretória, v. 26, n. 3, p.8-9, mar. 2019. Disponível em: 
<http://www.dod.mil.za/sasoldier/2019/Sold\%20Vol\%2026\%20No\%201\%20net.pdf>. Acesso em: 15 fev. 2020.

NGOMA, Naison. Civil-military relations in Africa: navigating uncharted waters. African Security Review, [S.L.], v. 15, n. 4, p. 98-111, jan. 2006. Informa UK Limited. http://dx.doi.org/10.1080/10246029.2006.9627624.

ONU. United Nations Organization Stabilization Mission in the DR Congo: Background. 2020. Disponível em: <https://monusco.unmissions.org/en/background>. Acesso em: 17 fev. 2020.

OTÁVIO, Anselmo. Quando a Pacificação se Transforma em Prioridade: a Atuação das Forças Armadas da África do Sul no Continente Africano. Revista de Estudos Internacionais, João Pessoa, v. 3, n. 8, p.293-310, jan./abr. 2017. Quadrimestral. Disponível em: <http://www.revistadeestudosinternacionais.com/uepb/index.php/rei/article/view/300/300>.

Acesso em: 15 fev. 2020.

TLHAOLE, Sargenteo Lebogang. SANDF marks 20 years of participation in peace missions. South African Soldier, Pretória, v. 26, n. 6, p.6-9, 2019. Disponível em: <http://www.dod.mil.za/sasoldier/2019/Sold\%20Vol\%2026\%20No\%206\%20net.pdf>. Acesso em: 15 fev. 2020.

TLHAOLE, Sargento Lebogang. Parliamentarians visit South African peacekeepers in the DRC. South African Soldier, Pretória, v. 25, n. 3, p.14-16, jan. 2018. Disponível em: <http://www.dod.mil.za/sasoldier/2018/Sold\%20Vol\%2025\%20No\%203\%20net.pdf>. Acesso em: 15 fev. 2020.

TLHAOLE, Sargento Lebogang. The SA National Defence Force is committed to African peace and security as part of the Force Intervention Brigade. South African Soldier, Pretória, v. 24, n. 2, p.18-20, 2017. Disponível em: <http://www.dod.mil.za/sasoldier/2017/Sold\%20Vol\%2024\%20No\%202\%202017\%20net.pdf>. Acesso em: 15 fev. 2020.

TRAVIS, Donald S.. Decoding Morris Janowitz: Limited War and Pragmatic Doctrine. Armed Forces \& Society, [s.l.], v. 46, n. 1, p.68-91, 21 mar. 2018. SAGE Publications.

TSHABALALA, Khanyisile Litchfield. The South African Military: From Apartheid SADF to the Transforming SANDF. In: TSHABALALA, Khanyisile Litchfield. Transformation in the Military Police Agency of the South African National Defence Force. Orientador: HERMAN CONRADIE. 2004. Dissertação (Mestrado em Artes) - University of South Africa, Pretória, 2004. $219 . \quad$ p. 2 Disponível https://citeseerx.ist.psu.edu/viewdoc/download?doi=10.1.1.940.546\&rep=rep1\&type=pdf. Acesso em: 3 fev. 2021.

TULL, Denis M.. The Limits and Unintended Consequences of UN Peace Enforcement: The Force Intervention Brigade in the DR Congo. International Peacekeeping, [s.l.], v. 25, n. 2, p.167-190, 2 ago. 2017.

UNESP. Tipos de revisão de literatura. Botucatu, 2015. Disponível em: https://www.fca.unesp.br/\#!/biblioteca/normas-tecnicas/tipos-de-revisao-de-literatura/. Acesso em: 28 jan. 2021.

WINGRIN, Dean. Defence Force set to recoup DRC expenses. 2017. DefenceWeb. Disponível em: https://www.defenceweb.co.za/sa-defence/sa-defence-sa-defence/defence-force-set-torecoup-drc-expenses/. Acesso em: 29 fev. 2020. 
YOUNG, K.. THE PROFESSIONAL SOLDIER. A Social and Political Portrait. By Morris Janowitz. Glencoe, Ill.: The Free Press, 1960. 464 pp. Social Forces, [s.l.], v. 39, n. 2, p.187-188, 1 dez. 1960. Oxford University Press (OUP). http://dx.doi.org/10.2307/2574160. Disponível em: <https://academic.oup.com/sf/article-abstract/39/2/187/2227037>. Acesso em: 16 fev. 2020. 